\title{
Effective Utilization of Pineapple Waste, Evaluation of Ferulic Acid, Micro Nutrients and Antioxidant Property ${ }^{\dagger}$
}

\author{
Madhu Meena S. ${ }^{\text {, Preetha R. }}{ }^{1, *}$ \\ 1 Department of Food Process Engineering, SRM Institute of Science and Technology, Kattangulathur, Chennai, 603203, \\ India, Tel: 9176610351 \\ * Correspondence: preethar@srmist.edu.in; \\ $\dagger$ Presented at International e-Conference on Bioengineering for Health and Environment (ICBHE 2020)
}

Received: 5.07.2020; Revised: 10.07.2020; Accepted: 12.07.2020; Published: 15.07.2020

\begin{abstract}
India is the second-largest producer of fruit and vegetable producers. Usually, after fruit intake, fruit peel is left as waste. The main bioactive components of pineapple are phenolic compounds, $\beta$-carotene, ascorbic acid, and flavonoids. Ferulic acid is a phenolic acid widely used in the nutritional and cosmetic fields. In this study pineapple peel was dried, powdered and vitamin content (A, B, B1, B2, B6, B12 \& C), calcium, potassium, phosphorus, iron, manganese, zinc and food fiber were analyzed. Moreover, in the present study, traditional and non-conventional processes such as Soxhlet extraction, supreme fluid extraction, and normal solvent extraction was used for the extraction of ferulic acid, which is a precursor for vanillin synthesis. The quantification of ferulic acid was done by High performance fluid chromatographic (HPL C) method. After the above-mentioned extraction process overall phenolic and antioxidant activity were also evaluated and compared. The highest concentrations of ferulic acid $(0.7696 \mathrm{~g} / 100 \mathrm{~g})$, phenolic compound (2.365mg / GAE), antioxidant activity (45 percent), and yield $(90.5 \%)$ were obtained for Soxhlet extraction using methanol.
\end{abstract}

Keywords: Bioactive compounds; Secondary metabolite; Ferulic acid; HPLC high performance liquid chromatography.

(C) 2020 by the authors. This article is an open access article distributed under the terms and conditions of the Creative Commons Attribution (CC BY) license (https://creativecommons.org/licenses/by/4.0/).

\section{Funding}

This research received no external funding.

\section{Acknowledgments}

This research has no acknowledgment.

\section{Conflicts of Interest}

The authors declare no conflict of interest. 